\title{
População em situação de rua: estigmas, preconceitos e estratégias de cuidado em saúde
}

\author{
Unhoused people: stigma, prejudice, and health care strategies
}

Cláudia Brito (https://orcid.org/0000-0002-7982-6918) ${ }^{1}$

Lenir Nascimento da Silva (https://orcid.org/0000-0002-9483-2873) ${ }^{1}$

${ }^{1}$ Programa de PósGraduação em Saúde Pública, Departamento de Administração e Planejamento em Saúde, Escola Nacional de Saúde Pública Sergio Arouca, Fundação Oswaldo Cruz. R. Leopoldo Bulhões 1480, Manguinhos. 21041-210 Rio de Janeiro RJ Brasil. Rio de Janeiro RJ Brasil. cbrito@ensp.fiocruz.br
Abstract Historical, social representations about stigma and prejudice related to unhoused people cause psychological distress, feeling of shame, and withdrawal from family and social relationships. This paper aimed to understand how unhoused people and health professionals perceive, reproduce, elaborate, and address the representations produced by their social conditions. This qualitative research employed participant observation, interviews with 24 unhoused people, and a focus group with professionals from the services providing care to the unhoused people. The study was conducted in Rio de Janeiro, Brazil, where crack use is very prevalent. An analysis was performed using the phenomenological narrative method. Stereotyping conjures the self-image of an unworthy, unwanted person, which justifies daily discrimination and, above all, the loss of the most critical condition of all beings, namely, their human condition, besides legitimizing the lack of care and violence against them. Deepening the relationship between prejudice and discrimination in the context of vulnerable populations and health services can assist therapeutic projects that promote the reduction of psychological distress, better care, and social recognition of citizenship of the unhoused people.

Key words Homeless people, Prejudice, Social discrimination, Health care, Health services
Resumo Representações sociais históricas sobre estigma e preconceito relacionado à População em Situação de Rua (PSR) provocam sofrimento psíquico, sentimento de vergonha, afastamento das relações familiares e sociais. Esse artigo objetivou entender como a PSR e os profissionais de saúde percebem, reproduzem, elaboram e lidam as representações produzidas por suas condições sociais. Pesquisa qualitativa, que envolve Observação Participante; Entrevistas com 24 PSR e Grupo Focal com profissionais dos serviços que prestam cuidado à PSR. O estudo foi realizado no município do Rio de Janeiro em local onde o uso do crack tem prevalência importante. Análise foi realizada pelo método da narrativa fenomenológica. $O$ estereótipo provoca uma autoimagem de pessoa indigna, indesejada, que justifica discriminações cotidianas e, sobretudo, a perda da condição mais importante de todos os seres: sua condição humana, além de legitimar desassistência e violência contra elas. Aprofundar as relações entre preconceitos e discriminações em contexto de população vulnerável e serviços de saúde, pode auxiliar projetos terapêuticos que promovam diminuição do sofrimento psíquico, melhor assistência e reconhecimento social de cidadania da PSR.

Palavras-chave Pessoas em situação de rua, Preconceito, Discriminação social, Assistência à saúde, Serviços de saúde 


\section{Introdução}

A história de vida da população em situação de rua (PSR) é marcada por perdas de vínculos, rupturas, desemprego, exclusão social e envolvimento, como produtora ou alvo, com atos violentos e criminosos ${ }^{1}$. Na sociedade, é rotineiro a tipificação da PSR como vagabunda, suja, louca, perigosa e coitada, o que contribui para legitimar a violência contra ela e servir de referência para suas identidades pessoais ${ }^{2}$ como pessoas com péssimas condições de vida, visíveis descuidos, odor desagradável ${ }^{3}$. Essas acepções alimentam barreiras e distanciamento entre PSR e população em geral, aumentando desconhecimento e atitudes de preconceito, desprezo, hostilidade e perversidade contra ela, conforme noticiado recorrentemente pela mídia. Apesar de viverem em situações de violência elevada, pobreza extrema e uso abusivo de álcool e outras drogas ${ }^{1}$, a maioria não é coberta por programas de inclusão social ${ }^{4}$ e políticas públicas voltadas para populações vulneráveis são implementadas de forma isolada e fragmentada, com importantes limitações na sua prática ${ }^{3}$.

Sob o ponto de vista da saúde, é alta a prevalência de doenças como Tuberculose, HIV/ Aids, dermatites, comorbidades psiquiátricas ${ }^{5}$ e uso abusivo de drogas ${ }^{1}$. O alcoolismo e outras drogas geralmente estão relacionados tanto com a manutenção das pessoas na rua, quanto com a exposição delas à violência.

A caracterização da PSR na literatura científica, em prontuários médicos, nas representações midiáticas e no senso comum perpassa por um conjunto de simbolismos sociais altamente estigmatizantes - extrema pobreza, desemprego, Tuberculose, Aids, doenças psiquiátricas, uso de drogas, "cracudo", pessoa violenta - o que implica em dificuldades de reintegração familiares e sociais.

Além destas representações depreciativas, recaem sobre a PSR os mesmos preconceitos e estigmas dos usuários de saúde mental, que restringem a reinserção na vida familiar, social e cultural $^{6}$, com perda do direito à cidade e à condição de cidadania ${ }^{7}$.

Nos espaços urbanos, a PSR é frequentemente impedida de entrar em locais como transporte coletivo, serviços de saúde, outros órgãos públi$\cos ^{4}$. Também é recorrente a tendência de responsabilizá-la por seus próprios problemas, sem levar em conta os contextos que os produziram.
Outra consequência negativa é a internalização e a reprodução destes preconceitos pela própria PSR, refletindo processo de identificação das representações sociais dirigidas contra ela ${ }^{3}$, seja pela família, pela sociedade, pela mídia, fruto de uma construção social histórica.

$\mathrm{O}$ efeito do neoliberalismo na descontinuidade de políticas sociais vem impactando negativamente nas condições de vida e trabalho, com evidências inequívocas no agravamento dos indicadores sociais. Em quatro anos, cresceu em 13,5 milhões o número de brasileiros em situação de pobreza, além dos 52,5 milhões já existentes ${ }^{8}$. O aumento de pessoas vivendo na rua é perceptível, e, nas regiões metropolitanas, esta população ganha uma nova visibilidade em decorrência da forte associação com o uso do crack e sua relação com aumento da criminalidade e violência urbana. Esse processo amplia a visão da PRS como pessoas incapazes de conviver, colocando-as continuamente como um risco para a sociedade e reforçando argumentos a favor da adoção de políticas públicas repressivas e arbitrárias.

A Política Nacional para inclusão social da PSR $^{9}$, criada em 2009, representou um grande avanço pela adoção de ações intersetoriais para reintegração às redes familiares e comunitárias e ampliação do acesso aos direitos constitucionais de cidadania, respeitando relações e vivência no espaço público da rua. Todavia, no Rio de Janeiro, pode-se dizer que os poderes públicos têm tratado essa questão na lógica da "limpeza urbana" e da "revitalização" dos espaços públicos. Alicerçados no discurso de "defesa da sociedade", promovem remoção, exclusão, criminalização e internação compulsória dos usuários de drogas e violação de direitos ${ }^{10}$. Temos ainda uma crescente radicalização do debate sobre drogas balizada por um neoconservadorismo recente, que recrudesce o aumento de ações como o recolhimento compulsório ${ }^{11}$.

Diante deste universo simbólico perverso ao qual a PSR está submetida, esse artigo objetivou entender como a PSR e os profissionais de saúde percebem, reproduzem, elaboram e lidam com as representações produzidas por suas condições sociais.

Aprofundar entendimento sobre construção de identidade no contexto de uma população vulnerável pode auxiliar projetos terapêuticos singulares que promovam diminuição do sofrimento psíquico e aumento da autoestima e do reconhecimento social de cidadania da PSR. 


\section{Método}

A pesquisa que dá origem ao artigo teve abordagem qualitativa, de perspectiva compreensiva e fenomenológica e postura reflexiva sobre o modo de vida e cuidado de saúde à PSR. O estudo foi desenvolvido no âmbito da Rede de Atenção à Saúde (RAS), prioritariamente junto ao Consultório na Rua (CnaR), em uma área programática do município do Rio de Janeiro, com alta prevalência de cracolândias, no período de março de 2017 a julho de 2019.

O CnaR é composto por uma equipe multiprofissional e representa a modalidade da Atenção Primária em Saúde (APS) que presta cuidado de saúde à PSR de fora itinerante, visando ampliar a oferta de cuidado integral e adequado às suas demandas e necessidades ${ }^{12}$.

A operacionalização da pesquisa foi construída por meio da combinação de três técnicas de investigação: (1) observação participante da prestação de cuidado de saúde; (2) entrevista com os pacientes do CnaR maiores de 18 anos e (3) grupo focal com os profissionais de saúde da RAS que atendem a PSR.

A observação participante ocorreu nos espaços de recepção e espera da PSR (para consulta e procedimentos, alimentação, banho, doação de roupas ou itens de higiene); de atendimentos diversos (consulta, procedimento, curativo, resultado de exames); cenas no território (barracos, cenas de uso de drogas, ruas, Unidades de Pronto -Atendimento, Hospitais, equipamentos sociais, outros) e reuniões de equipe do CnaR.

As observações foram realizadas de forma exclusiva nos primeiros 18 meses da pesquisa, em alguns turnos por semana, seguindo de forma mais flexível, por mais seis meses, durante o período das entrevistas. $\mathrm{O}$ entrevistado foi abordado no espaço de espera, mencionado acima, e a entrevista realizada em sala com privacidade. Não houve critério de seleção para participação, visando atender a pluralidade de pessoas. Os excluídos foram exclusivamente por contraindicação clínica (Tuberculose infectante ou atendimento de urgência). As questões das entrevistas partiram de um roteiro prévio, mas foram conduzidas de forma aberta, com possibilidade de o livre fluir do relato, permitindo que o fenômeno se mostrasse na própria linguagem. Foram entrevistadas 24 pessoas em situação de rua e realizados três encontros de grupo focal com profissionais de saúde de diversos dispositivos da RAS que prestam cuidado de saúde da PSR no território estudado.
Para análise, utilizou-se a transcrição dos áudios das entrevistas e dos grupos focais e anotações do diário de campo. O material transcrito foi tratado com o pressuposto de que a narrativa é tudo o que se tem, visto que não há acesso aos "fatos" e, portanto, não foram feitos julgamentos sobre a veracidade ou não dos relatos. Nesse tocante, adotamos a abordagem etnográfica ${ }^{13} \mathrm{de}$ "levar a sério" os entrevistados, estabelecendo as categorias que fazem sentido para eles. Com o método da narrativa fenomenológica, foi realizado agrupamento do material em unidades de sentido e, posteriormente, fez-se uma descrição dialógica entre os sujeitos, tornando-a histórica, singular e coletiva.

A condução das entrevistas de forma fluida, atendendo aos objetivos da pesquisa por meio das histórias de vida, possibilitou a emersão de categorias empíricas sobre uma imagem de si, preconceitos, medos e sofrimentos percebidos pela PSR. Essas categorias puderam ser reveladas mesmo na ausência de uma pergunta direta, potencializando uma narrativa mais inconsciente e menos arrumada. Da mesma forma, a partir do material analisado, também afloraram percepções dos profissionais de saúde sobre preconceitos e estigmas vividos pela PSR, bem como estratégias de cuidado para mitigar esses efeitos danosos. Fragmentos das narrativas ipsi literis estão assinaladas com aspas para auxiliar na descrição das análises.

Esta pesquisa teve aprovação dos Comitês de Ética em Pesquisa da Escola Nacional de Saúde Pública Sergio Arouca e da Secretaria Municipal de Saúde e Defesa Civil do Rio de Janeiro.

\section{Resultado}

\section{Caracterização dos entrevistados e impressões dos pesquisadores}

No panorama sociodemográfico geral, as pessoas entrevistadas eram majoritariamente do sexo masculino $(\mathrm{N}=14)$; na faixa etária entre 30 e 60 anos; de raça negra, com 1/3 de raça branca; metade tinha Ensino Médio ou Superior Completo e 1/3 era analfabeto ou tinha estudado até o primeiro seguimento do Ensino Fundamental; todos eram naturais da Região Sudeste. Metade dos entrevistados estava por mais de 5 anos na rua e todos já haviam usado ou estavam em uso de drogas, sendo que metade mencionou uso do crack. Embora a maior parte fosse oriunda da classe baixa, um terço dos entrevistados era pro- 
veniente das classes média e média-alta, o que nos causou certa surpresa e reflexão acerca da ideia preconcebida, também em nós, de que quase a totalidade da PSR era nativo da classe social baixa.

Desde o início das entrevistas ficamos surpresos com a revelação de uma grande parte dos entrevistados com uma visão preconceituosa de si, em especial ligada à droga ou ao crack, mas também ligada às doenças psiquiátricas e ao trabalho de "catação". Também foi observado o preconceito que a PSR sofre e sente "nos olhares" do cidadão comum ou de profissionais de serviços públicos, bem como reações e estratégias que ambos (PSR e profissionais de saúde) recorrem para mitigá-lo, tendo em vista o longo caminho até sua superação.

Se o preconceito se manifesta por ações verbais e não-verbais, essas também podem produzir potência do cuidado subjetivo, por meio do toque acolhedor, do olhar interessado, da escuta atenta, da atuação contínua no território e da produção de acolhida e vínculo.

Pode-se observar sinais de autopreconceito na surpresa e "felicidade" que essas pessoas demonstravam ao receber um abraço dos pesquisadores, assim como em falas do tipo: "pode abraçar [de novo], porque eu não tenho piolho não”.

\section{Expressões de preconceito nas narrativas da PSR}

A partir das narrativas sobre modo e história de vida da PSR foi possível perceber preconceitos vividos e (re)produzidos por ela, sendo os mais expressivos aqueles relacionados à forma de sustento (catação, prostituição), à doença (psíquica, Tuberculose, HIV), ao uso abusivo de crack e à imagem de si.

Homem, 56 anos, trabalhador orgulhoso, fala sobre o irmão falecido:

[...] eu tinha um irmão que era problemático, que não trabalhava. Ele era usuário também de droga e... pegou um espírito... ruim, de andar todo sujo na rua, catando essas coisa, é garrafa, é lata, essas coisa toda. Isso é espírito ruim que entra na pessoa. Porque não é normal a pessoa sair catando aquilo ali e andar todo sujo no meio da rua. Aí eles vão na força da droga catando tudo, mete a mão em tudo que é lugar. Em lixeira, em tudo. [...] Só vive assim fuçando igual cachorro dentro do lixo. Isso é espírito ruim que entrou no meu irmão e tem um montão deles na rua, aí, você vê.

Em outro momento, o entrevistado discorre sobre a prática de propina no local que costuma trabalhar como vendedor ambulante:
Sexta-feira todas delegacias têm um dinheiro por fora, [...] A contravenção existe porque tem propina, senão, não existiria. Se tem ladrão de carro é porque tem ferro velho. Mas não é jogo acabar com ferro velho. Se todo mundo andar direito, ninguém quer ser polícia porque não tem propina. Cê vai querer ganhar um salário mínimo pra de repente tomar um tiro aí na rua? Não vai, vai?! [...] O salário da PM não chega quatro, cinco mil, você chega no estacionamento da PM e vê carro importado de cento e cinquenta mil. Fala tu, como é que vai comprar? Se o cara tem que pagar escola particular pro filho, pra filha, aluguel, que ele não vai morar dentro de favela. [...] Ele é polícia, se ele morar neguinho vai matar ele. E como ele consegue ainda ter um carro no valor de cem, cento e cinquenta mil? É a propina. Se todo mundo andasse certo, meu filho, porra, o cara não queria nem ser Presidente da República, porque não ia arrumar nada.

$\mathrm{O}$ entrevistado que se mostrava orgulhoso de não se parecer com "morador de rua" e da caixa de isopor destinada à venda de salgados que portava, desvela seus valores sobre o mundo do trabalho enquanto símbolo de reconhecimento social e dignidade humana. Em contrapartida, avalia atividades de sustento e sobrevivência comum da PSR (catação, garimpo, reciclagem) com reprovação, fazendo analogia a um comportamento animalesco. A "catação", relacionada pela provável doença psiquiátrica do irmão, é denominada de "espírito ruim", termo recorrente nos discursos das igrejas neopentecostais, mostra que portadores de doenças mentais em situação de rua são alvos de preconceito exacerbado.

Por outro lado, a narrativa também desvela o cinismo do mundo corporativo e das instituições. O alto poder de observação e lucidez do entrevistado carece de autocrítica e serve de justificativa, reforçando valores capitalistas que determinam que "tudo pode", para tudo há uma desculpa. Assim, instituições não têm o "espírito ruim", mesmo que apresentem um comportamento reprovável.

O relato também ilustra ambiguidade, no qual "catação" tem tom pejorativo, depreciativo e preconceituoso, enquanto atenua e normaliza recebimento de propinas por policiais. De certo, esses preconceitos por vezes são contraditórios, mostrando que o peso do julgamento da PSR é mais cruel com ela do que com a população em geral, reproduzindo o status quo da sociedade.

Homem, de 54 anos, foi para rua pelo medo de assassinar o próprio filho, como consequência de surtos psicóticos, fala da dificuldade com diagnóstico psiquiátrico: 
O remédio me incomoda, me incomoda. Porque me dá essa sensação de loucura, sabe? [...] Essas vozes, ... pra mim seria mais fácil, eu queria ouvir tanto que isso [esquizofrenia] era espiritual, entendeu? Tinha tanta vontade de alguém, nessa internação que eu tô, é religiosa, ela é católica, né. Eu tinha muita vontade de que eles falassem pra mim que era espiritual. Queria tanto ouvir isso, mas eles falaram que isso é, isso é mental. Isso é minha mente. Confirmaram o que eu já sabia, entendeu? [...] que a minha mente é que cria isso tudo.

Depois de perder as esperanças sobre seu diagnóstico não ser de cunho espiritual, busca uma nova causa para sua doença, mesmo que não faça mais uso do crack:

o crack me deixou com algumas sequelas, de ouvir vozes...

O relato mostra os desdobramentos paradoxais da doença mental: vivenciar sofrimento, discriminação, estigma, medicalização da vida e seus efeitos colaterais. Para o entrevistado, mesmo que a medicação aliviasse as alucinações, de certo modo, ela era a prova incontestável da sua situação psiquiátrica, da qual deseja se livrar. A busca de um culpado externo (medicação, "encosto", energia negativa, crack) para uma doença crônica, representa alívio e perspectiva de "cura" para uma condição que é inaceitável para o paciente, tendo em vista que essas condições são passíveis de tratamento. Loucura para o entrevistado representa dois motivos de sofrimento: sintomas (alucinações) e preconceito com ela.

Mulher, 38 anos, graduação em História, Psicologia e Terapia Ocupacional

O motivo que eu vim pra cá é que eu tenho o maior preconceito com tratamento de Tuberculose ... e aí, eu confio na [profissional de saúde]. Eu tô com Tuberculose, começo tratamento e paro, começo e paro.

A entrevistada mostra o autopreconceito por outra doença estigmatizada socialmente e, igualmente, a prática de interrupção de tratamento para doenças contra as quais se tem preconceito ou não-aceitação. Salienta, ainda, que vínculo e relação de confiança favorecem o tratamento de doenças estigmatizantes.

Outros entrevistados mostraram diversas expressões de estigma e preconceito por causa do uso do crack:

Eu uso crack, eu tô usando pedra, mas eu não fico em cracolândia, eu tenho vergonha de ficar em cracolândia, entendeu? (Homem, 45 anos, evangélico e entregador).

O problema não é a droga, é ser pego; o crack é problema pra família, pelo preconceito. (Homem, 35 anos, sofre de solidão).
Falam aí que eu sou viado só porque eu não pego cracuda. É cracudinha, na verdade cracuda, pego mesmo não, já não chega eu sujo. Ah! É mulher, mas a pessoa não toma um banho, o que é isso?! [...] Todos nós sabemos que a mulher que é limpa é normal. (Homem, 29 anos, usuário de crack).

O meu irmão, que é crente há quarenta anos, falou que o desejo dele é me ver morto dentro do caixão. [...] Por causa do crack. Porque ele é preconceituoso. [...] O crack pra mim é como Risperidona, Clorpromazina, Ácido valpróico, Diazepam... Faz parte. Eu uso toda hora. Eu dependo do crack também e da maconha, junto com os remédios, esses que eu falei [...] para conseguir estabilizar mais essa coisa que é a minha cabeça, porque você não tem ideia do que é viver com todos esses pensamentos [esquizofrênicos]. E quando todos eles vêm numa porrada só? Quando eu uso crack eu fico assim, do jeito que eu estou, normal. Não há diferença. Sem crack complica, porque aí eu vou ter que aumentar muito as medicações legais, e aí eu vou virar um ve-ge-tal. (Homem, 47 anos, viciado em ler).

Além dos relatos em destaque, diversos entrevistados deixaram entrever preconceitos contra usuários de drogas ("viciados", "não gosto de adictos”, “cracudos”), mesmo que eles próprios fizessem uso compulsivo do crack.

O crack, além das consequências deletérias físicas e psíquicas relacionadas ao seu uso e das dificuldades de abstinência, também é motivo de sofrimentos decorrentes do sentimento de vergonha e rupturas familiares. Entre os dependentes de drogas, o crack é tido como o pior dos mundos, estendendo esse estereótipo aos seus usuários. A condição de ser mulher, moradora de rua e usuária de crack personifica a combinação de triplo preconceito decorrente dos valores conservadores e sexistas ainda presentes na sociedade em geral, que se reproduzem também em quem vive na rua.

Um entrevistado mostra sofrimento tanto pela falta de controle dos sintomas psiquiátricos, quanto pelo efeito colateral alienante das medicações psiquiátricas e argumenta que não vê distinção entre uso de drogas lícitas (prescritas pela medicina) e ilícitas para o controle dos pensamentos alucinógenos e paranoicos que sofre. Tenciona um tema ainda tabu na sociedade, e com fortes entraves da ideologia conservadora, para aprofundar essa discussão.

Outras narrativas abrigaram preconceitos de alguns moradores de rua contra a própria PSR, percebidos pelas expressões: "bandos", "maloqueiros", "pessoal que não toma banho". Alguns mostraram preconceitos em relação às doenças/ 
condições comuns nesses grupos (dependência química, Transtorno Mental, HIV/Tuberculose: "não aceito", "não mereço") e ainda contra a prostituição, percebida pelo uso de termos ambíguos, como: "troca”, "dinheiro que cai do céu”. O "autopreconceito" fica evidente quando o próprio sujeito de certo grupo ou atividade (uso de crack) julga moralmente o semelhante. Isso mostra que, de algum modo, tais pessoas se veem "dentro" e também "fora” desses grupos. O preconceito representa o esforço que o sujeito faz para se diferenciar e não pertencer àquele grupo. É notório também a reprodução de preconceitos e discriminação da sociedade em geral pela própria PSR.

A negação como medida para se afastar daquilo que se tem preconceito mostra o grau de sofrimento psíquico ao qual essas pessoas estão expostas e sentem em decorrência de estigmas e discriminação.

\section{Expressão de preconceitos e discriminação no contexto do cuidado de saúde}

Diversos entrevistados relatam casos em que se percebem serem alvos de preconceitos dos outros, principalmente em serviços de saúde.

Mulher, 43 anos, usuária de crack, HIV+, sonho de ser mãe

Porque eu gosto de vim aqui [CnaR], porque aqui eu sou tratada bem. Nos outros, eles olham a gente assim, com cara de nojo. Às vezes dá sorte de pegar ... um médico legal, que te trata como um ser humano, mas eu vou falar uma coisa pra você. Eu tenho o maior medo, sabe por causa de quê? Eu tenho medo de chegar lá, e tem gente que tem ódio de cracudo. [...] Aí vem o meu medo. [...] Ah! a cracuda aí, vai ficar ocupando espaço de gente doente, dá logo uma injeção na veia dela, mata logo ...” "Ah! já tem HIV memo"... Até eu fazer ... a beópsia de não sei o quê, eu já morri

[Quando] chego no hospital, eu já chego assim, "Oi, tudo bem? Prazer, meu nome é [...], eu sou usuária de crack, mas não sou... ". Já chego me comunicando, pegando amizade, porque eu não sou boba, tenho medo de eles me darem uma injeção... e eu morrer.

Mulher, 32 anos, na rua desde os 17 anos.

Nos outros lugares eu fui atendida mais ou menos. Nem quando eu fiquei internada [...] teve também lá... preconceito, desmerecimento de uns enfermeiros, de uns médicos [...] por não ter endereço fixo, ser usuária. Porque eu não escondo, eu sou usuária mesmo, eu vou esconder pra quê? Aí houve aquela discriminação, às vezes de... eu pedir uma coisa, estar precisando daquilo, nem tchum, não atender.

Os relatos mostram os receios da PSR frente às ações motivadas por preconceitos durante atendimento de saúde nos serviços da RAS. A representação de "sujeito sem documento, não domiciliado, usuário de droga" constrói uma autoimagem negativa nessas pessoas, que passam a se sentir indignas e indesejadas. Esse processo contínuo pode levar à perda do atributo mais importante de todos seres: sua condição humana. A pessoa que é constantemente colocada no lugar do indesejado perde o direito à cidadania e à vida.

Muitas vezes, a estratégia utilizada pela PSR para reverter a discriminação e ser cuidada pelos serviços de saúde é reagindo dentro das suas possibilidades: sendo comunicativa, pegando amizade e priorizando serviços de confiança. Em suma, mostrando que ali tem um ser humano capaz de agir, interagir e reagir.

\section{Percepções de profissionais de saúde sobre preconceito e discriminação contra a PSR}

Os profissionais de saúde participantes da pesquisa compartilharam a mesma preocupação com o preconceito e a discriminação que a PSR enfrenta nos serviços de saúde, seja vindo de profissionais, de outros pacientes, ou mesmo na priorização de condutas mais autoritárias ou restritivas de autonomia, exclusivamente por se tratar de PSR. Foi unanime o reconhecimento de que dependente químico em situação de rua tem uma dupla carga de preconceito e discriminação na relação com os serviços de saúde.

De acordo com esses profissionais, as discriminações no cotidiano dos serviços podem ser distintas:

um olhar discriminatório; não atendimento quando acionado por ser PSR; coloca diagnóstico 'situação de rua' ou 'social' e nem escuta o paciente; induz o Conselho Tutelar a tirar a guarda da criança que nasce de moradora de rua drogada; profissionais que só pensam na proteção da criança e desprezam a mãe. É a prática da Assistente Social da mão pesada; às vezes, por acreditar que a PSR não vai dar conta dos desdobramentos do procedimento, optam por procedimentos menos indicados, como por exemplo uso do gesso ao invés de cirurgia porque não sabem como faria o pós-operatório; quando é usuário [de drogas] existe sempre a preleção do tratamento da droga em detrimento de qualquer outro diagnóstico.

Além da desassistência, os relatos mostram a prática de cuidado negligente ou inapropriado, 
seja pelo hipercuidado ou subcuidado, motivado pelo simples fato de o profissional de saúde desconhecer as condições e redes de apoio da PRS e sequer perguntar por suas preferências. Pacientes em situação de rua, tratados como sujeitos desprovidos de desejos e escolhas, ficam à mercê dos valores, crenças e prioridades dos profissionais em relação ao cuidado de saúde, reiterando a relação de exclusão da PSR consigo e com o mundo.

Além disso, foi mencionado comportamento discriminatório de outros pacientes com moradores de rua nos serviços de saúde: "tem pacientes que não aceitam ser atendidos depois da população de rua, mesmo que tenha chegado depois dela".

O preconceito no cuidado de saúde da PSR escancara a prática em que a "vida" da pessoa não depende da sua condição de saúde, mas da conduta de cada profissional, agravando ainda mais a vulnerabilidade desta população.

Para minimizar os efeitos deletérios da atuação dos serviços de saúde, profissionais do CnaR compartilharam suas estratégias para combater discriminação e prover cuidado, seja por meio do constrangimento, da vigília dos serviços de saúde para evitar alta precoce ou desassistência, seja pelo atendimento do paciente, independente da forma como ele atue para obtenção do cuidado.

Ás vezes a gente leva na van a Portaria [que institui] do cartão do SUS, [...] não tá falando de CPF [na portaria] no Cartão SUS, [...] pergunta o nome da mãe e o nome todo da pessoa.... Aí rola o constrangimento [...] pra aquilo ser efetivado."

"Precisa ter algum profissional que se sensibiliza com a PSR para que ela seja tratada como outro qualquer.

A equipe tomou conta, né? O dentista não arredou mais o pé, a [profissional de saúde] também não arredou mais de perto da UPA enquanto o [paciente] não saiu de lá, do caso estar resolvido, de estar na emergência. É assim que funciona o consultório da rua.

Quando ele chega [...] vai naquele impacto do terror mesmo ou ele vai de "sou coitadinho" [...] só que com o tempo, ele vai entendendo que a gente tá ali independente de qual história ele tem pra contar, e que a gente vai atender ele de qualquer forma.

Outra forma de reduzir preconceito é por meio da aproximação da realidade. Residente compartilha sua reflexão sobre uma cracolândia, durante o trajeto até o cuidado itinerante.

Quando você entra realmente na cena, você vê que não tem nada daquilo, não vai ter ninguém te atacando, ninguém sendo violento com você, te roubando com arma. Você vê pessoas sofrendo em condições desumanas que estão carentes de afeto.
A reflexão mostra o contraste da visão de quem vê a cena da rodovia, de dentro de um automóvel, e de quem entra na cena. O desconhecimento da realidade projeta uma situação bem mais perigosa do que a sentida na experiência. Desta forma, o conhecimento é mais uma possibilidade de atenuar preconceitos, de quebrar barreiras e diminuir indiferenças com a PSR.

\section{Discussão}

Esse artigo objetivou identificar como preconceito e estigma atingem a PSR e destacar formas de ultrapassar as barreiras sociais inseridas dentro dos serviços de saúde. A existência de representações sociais pejorativas em relação à PSR, que se materializam nas relações sociais não é algo novo na literatura acadêmica ${ }^{1-4,6,9}$. Todavia, poucos abordam o autopreconceito ou seus efeitos produzidos no âmbito do cuidado de saúde.

Um olhar de "repugnância" dirigido ao semelhante representa regras e valores da sociedade vigente internalizadas pelas pessoas que vivem na rua, como pode ser visto na depreciação de atividades como catação e prostituição, além da opinião de que mulher tem que ser limpa (homem não). Esse processo propicia que a PSR utilize rótulos depreciativos como referência para configurarem suas próprias identidades ${ }^{2}$. Por conseguinte, a incorporação de uma visão pejorativa de si, propicia, pouco a pouco, a construção de uma identidade de "caídos, inúteis, fracassados"14. Essas construções sociais implicam em maiores dificuldades na reinserção familiar e social ${ }^{2}$, inclusive com irmão preferindo a morte do entrevistado por vergonha dele ser usuário de crack.

Sobre preconceito e Tuberculose, Snowden ${ }^{15}$ salienta que existem patologias com maior prevalência nas condições de pobreza, doenças com poder histórico de mobilizar a opinião pública contra pobres, reforçando mecanismos de estigmatização que promovem a exclusão social ${ }^{15}$. Acerca desse fato, a PSR demonstra preconceito justamente com doenças relacionadas socialmente com a pobreza. Além disso, a pesquisa mostrou que a "não-aceitação" e o preconceito com diagnósticos estigmatizantes interfere na continuidade do tratamento de doenças com graves consequências para a saúde e vida do paciente e seu grupo de convívio.

A reprodução dos preconceitos da sociedade pela PSR mostra convergência de valores e crenças e levanta o questionamento se a PSR está mesmo à margem da sociedade, ou se ela é con- 
siderada marginal apenas na garantia ao direito constitucional, como expresso no artigo quinto: “Todos são iguais perante a lei”. Desassistência e negligência por parte de profissionais de saúde e pacientes demandando passar à frente da PSR nos serviços de saúde, apenas por sua condição social e não de saúde, são exemplos de violação destes direitos.

A pesquisa mostra a relação entre preconceito e temas tabus, como uso de drogas ilícitas, prostituição e alerta que a falta de conhecimento e diálogo sobre esses conteúdos interditados alimentam o sofrimento psíquico, limitando possibilidades nos cuidados de saúde, tais como: tratamento da droga em detrimento de qualquer outro diagnóstico, prática da Assistente Social da mão pesada, dentre outros. Ademais, a dimensão religiosa na reprodução de preconceitos e "jargões" pela PSR, sobretudo oriundos de religiões neopentecostais, expõe a relação de competição entre saúde e práticas religiosas, que pode ser prejudicial para a terapêutica dos usuários ${ }^{6}$.

A Reforma Psiquiátrica Brasileira, mesmo enquanto campo em construção, trouxe avanços inestimáveis no discurso e prática para lidar com a loucura e o sofrimento mental, aversa à institucionalização da loucura ${ }^{7}$. Contudo, apesar da imbricada relação entre PSR e Saúde Mental, pessoas em situação de rua não se beneficiaram de suas conquistas como poderiam. Além disso, a Política para inclusão da $\operatorname{PSR}^{9}$ é recente e não alcançou o movimento revolucionário e os avanços da Reforma Psiquiátrica. Asilos, Hospitais e abrigos parecem produzir um processo de institucionalização e desfiguração da subjetividade, tal como a rua - uma institucionalização sem instituição.

Arendt ${ }^{16}$, a partir de reflexões sobre campos de concentração, detalha o processo de transformação de cidadãos de direito em "mortos-vivos" - sujeitos indesejados, considerados sem valor, sem pertencimento, supérfluos. Para ela ${ }^{16}$, "morto-vivo" é aquele tratado como se não existisse, como se os acontecimentos de sua vida não interessassem a ninguém, como se estivesse morto ${ }^{16}$. Os métodos de preparação dessa condição são histórica e politicamente explicáveis, distinguindo-se pelas práticas de eliminar sistematicamente o direito, a moral e a singularidade das pessoas ${ }^{16}$. $\mathrm{O}$ abandono de si e a perda da espontaneidade são consequências dessas práticas e foram observadas nessa pesquisa ${ }^{16}$.
De forma análoga, Gofman ${ }^{17}$ descreve o processo de "mortificação do eu" como produção de tensão psicológica aguda, com degradações e humilhações, sobre o indivíduo desiludido do mundo ou sentimento de culpa, de modo que a mortificação pode provocar alívio psicológico.

As práticas que destituem a pessoa de sua cidadania ${ }^{16}$ repercutem em diversos aspectos da vida de um indivíduo, produzindo sentimentos de vergonha e humilhação, provocando afastamento familiar, isolamento ou formação de grupos que lhe confira uma identidade estável ${ }^{2}$.

Preconceito, discriminação e desassistência têm uma atuação direta nesse processo. Essas vivências somadas - na família, nos serviços e na sociedade - atuam na transformação do cidadão em "morto-vivo" ou na "mortificação do eu", afetando a autoimagem e autoestima da PSR, provocando descaso no atendimento de pessoas justamente com as maiores necessidades sociais.

Escorel $^{18}$ fala de pessoas que "vivem de teimosas", visto que mesmo com a redução dos seus campos de possibilidades, rompem com estas restrições, criam novas oportunidades de constituir-se enquanto protagonistas ativos da mesma sociedade que lhes nega oportunidades.

De forma não intencional, a pesquisa pôde refletir sobre estigmas, preconceitos, vergonhas, medos e sobre formas inconscientes de superação, como possibilidades de transformação de realidades desprovidas de esperança.

A priorização de estudar a PSR a partir de sua história de vida objetivou a sua valorização como sujeitos ativos e protagonistas de histórias, trajetórias, valores, em contraponto com a marca de invisibilidade, desconhecimento e preconceito que é frequentemente caracterizada.

Quanto às limitações do artigo, destaca-se o fato de a população de estudo ter alta prevalência de uso de drogas, sobretudo o crack, o que pode ter colocado em evidência essa questão, além de a pesquisa originária não ter tido intuito direto de estudar preconceito e discriminação, podendo ter limitado esse tema. Contudo, o fato do preconceito ter sido tão evidenciado, tanto pela PSR e por profissionais de saúde, em uma pesquisa sem essa finalidade, mostra a latência dessas questões e o sofrimento que isso traz, para quem é cuidado e quem cuida. Nesse sentido, reforçase a importância de novos estudos investigativos sobre preconceito e mulheres em situação de rua, preconceitos e interrupção de tratamento de saúde e estratégias para enfrentá-lo. 


\section{Conclusão}

Resultados mostram que, de forma contraditória, os principais preconceitos (re)produzidos pela PSR contra si, são também aqueles que representam a sua identidade no imaginário da sociedade, relacionando-se com sua aparência descuidada e malcheirosa, sua forma de sustento, doenças mais prevalentes (Transtorno Mental, Tuberculose, HIV) e ao uso de drogas, sobretudo crack.

De forma similar ao status quo, ser mulher em situação de rua e usuária de drogas mostrouse como uma importante combinação discriminatória, somando-se aos preconceitos sexistas e aos sociais. Do mesmo modo, sofrer de transtorno mental e estar em situação de rua aumentam estigmas e, consequentemente, sofrimento psíquico dos sujeitos. A PSR coloca em evidência o tabu social e a resistência ao debate sobre drogas prescritas pela medicina e ilícitas, implicando em consequências no âmbito da saúde e da violência.

Todo esse processo discriminatório mostrou que ele não é inócuo, e produz sim, muitos efeitos deletérios, como: sofrimento, baixa autoestima, rupturas familiares e exclusões sociais, destituição da condição de direito e cidadania, abandono de tratamento e desassistência.

Em contrapartida, estratégias para lidar com o sofrimento frente aos preconceitos sofridos são: não se parecer com 'morador de rua', ficar longe de cracolândias; autonegação e abandono do tratamento de doenças estigmatizantes.

Nos serviços de saúde, evidencia-se a discriminação da qual a PSR é alvo, seja pela aparência, falta de documentos, de domicílio ou pelo uso de drogas, e esse estereótipo justifica desassistência e cerceamento do direito, da cidadania e da vida.

Ciente de sua condição enquanto ser preterível e indesejado, a PSR tentar driblar sua desvantagem e se manter viva sendo comunicativa, pegando amizade, e priorizando serviços de confiança, mostrando que a Política para inclusão da PSR $^{9}$ e a instituição dos $\mathrm{CnaR}^{12}$ foram grandes avanços da vida, do respeito à diversidade e dos Direitos Humanos. A equipe do CnaR e outros profissionais sensíveis às agressões não-verbais sofridas pela PSR somam forças e adotam estratégias de combate à discriminação em prol da vida, ora por meio de constrangimento, vigília dos serviços de saúde para evitar desassistência, ora por meio de atitudes sensíveis do profissional, olhar interessado, escuta atenta ou busca incessante do sujeito pelo território. A relação de vínculo e confiança com serviços de saúde favorece a persistência do tratamento de doenças que produzem efeitos importantes quando descontinuadas. Cuidar em favor da vida começa por um cuidado empático. Ações solidárias tem o potencial de atenuar sofrimentos e desiguldades e produzir subjetividades, desejos e projetos de autonomia ${ }^{19}$.

Refletir sobre ações reproduzidas de forma mecanizadas e efeitos desastrosos dos preconceitos, além de conhecer a realidade sob julgamento, auxilia a descontruir barreiras, aproximar diálogos e contribuir para uma vida mais equilibrada e equitativa. Estudos nessa área podem contribuir para aprimorar as políticas públicas e diminuir a distância que coabita espaços urbanos com tamanha disparidade social.

\section{Colaboradores}

C Brito e LN Silva participaram da concepção, análise, redação e revisão crítica do manuscrito. 


\section{Referências}

1. Brasil. Ministério da Saúde (MS). Manual sobre o cuidado à saúde junto a população em situação de rua. Brasília: MS; 2012. (Série A. Normas e Manuais Técnicos)

2. Mattos RM, Ferreira RF. Quem vocês pensam que (elas) são? - Representações sobre as pessoas em situação de rua. Psicol Soc 2004; 16(2):47-58.

3. Campos A G, Souza M P F. Violência muda e preconceito: estratégias de uma equipe de saúde em defesa da cidadania da população de rua. BIS Bol Inst Saúde [Internet] 2013 [acessado 2020 out 29]; 14(3):344-351. Disponível em: http://periodicos. ses.sp.bvs.br/scielo.php?script $=$ sci_arttext\&pi$\mathrm{d}=\mathrm{S} 1518-18122013000400013 \& \operatorname{lng}=\mathrm{pt}$.

4. Brasil. Pesquisa nacional sobre a população em situação de rua. Brasília: Ministério do Desenvolvimento Social e Combate à Fome; 2008.

5. Halpern SC, Scherer JN, Roglio V, Faller S, Sordi A, Ornell F, Dalbosco C, Pechansky F, Kessler F, Diemen LV. Vulnerabilidades clínicas e sociais em usuários de crack de acordo com a situação de moradia: um estudo multicêntrico de seis capitais brasileiras. Cad Saude Publica 2017; 33(6):e00037517.

6. Brasil. Departamento de Ações Programáticas Estratégicas. Saúde Mental. Brasília: Ministério da Saúde, 2015. 548 p.: il. (Caderno HumanizaSUS; v. 5; Saúde Mental). [acessado 2020 jul 3]. Disponível em: https://bvsms.saude.gov.br/bvs/publicacoes/saude_ mental_volume_5.pdf

7. Amarante P, Torre EHG. "De volta à cidade, sr. cidadão!" - reforma psiquiátrica e participação social: do isolamento institucional ao movimento antimanicomial. Revista de Administração Pública 2018; 52(6):1090-1107.

8. Instituto Brasileiro de Geografia e Estatística (IBGE). Sintese de Indicadores Sociais 2019: Uma análise das condições de vida da população brasileira. Rio de Janeiro: IBGE; 2019.

9. Brasil. Decreto Presidencial no 7.053, de 23 de dezembro de 2009. Institui a Política Nacional para a População em Situação de Rua e seu Comitê Intersetorial de Acompanhamento e Monitoramento, e dá outras providências. Diário Oficial da União 2009; 24 dez.

10. Monteiro MMFC. A dimensão da intersetorialidade nas práticas do consultório na rua: a experiência do Rio de Janeiro. 107 f [dissertação]. Rio de Janeiro: Escola Nacional de Saúde Pública Sergio Arouca, Fundação Oswaldo Cruz; 2019.
11. Bastos FI. Apresentação do perfil epidemiológico dos usuários de crack: pesquisa social com a apresentação do recorte do perfil de Manguinhos. In: Teixeira M, Fonseca Z, organizadores. Saberes e práticas na Atenção Primária à Saúde Cuidado à População em Situação de Rua e Usuários de Álcool, Crack e Outras Drogas. São Paulo: Hucitec Editora; 2015.

12. Brasil. Ministério da Saúde (MS). Portaria número 122, de 25 de janeiro de 2012. Define as diretrizes de organização e funcionamento das Equipes de Consultório na Rua. Diário Oficial [da] República Federativa do Brasil. 25 Jan 2012.

13. Evans-Pritchard EE. Os Nuer. São Paulo: Perspectiva; 1978.

14. Zaluar A. Comentários dos assessores sobre o perfil da população de rua. In: Rosa CMMborganizadores. População de rua: Brasil-Canadá. São Paulo: Hucitec; 1995. p. 53-61.

15. Snowden FM. Epidemics and Society From the Black Death to the Present. New Haven: Yale University Press; 2020.608 pp.

16. Arendt H. The Concentration Camps. New York City: The Partisan Review; 1948. pp. 743-763.

17. Goffman E. Manicômios, prisões, conventos. Rio de Janeiro: Graal; 1978.

18. Escorel S. Vivendo de teimosos: moradores de rua da cidade do Rio de Janeiro In: Bursztyn M, organizadores. No meio da rua: nômades excluídos e viradores. Rio de Janeiro: Garamond; 2000. p. 139-171.

19. Pires MRGM. Politicidade do cuidado e processo de trabalho em saúde: conhecer para cuidar melhor, cuidar para confrontar, cuidar para emancipar. Cien Saude Colet 2005; 10(4):1025-1035

Artigo apresentado em 31/10/2020

Aprovado em 13/10/2021

Versão final apresentada em 15/10/2021

Editores-chefes: Romeu Gomes, Antônio Augusto Moura da Silva 